\title{
COMPARISON OF DIFFERENT PHENOTYPIC METHODS FOR AMPC DETECTION
}

\author{
Mohd. Rashid', Huma Naim², Mohd. Khalid³, Indu Shukla ${ }^{4}$
}

1Associate Professor, Department of Microbiology, F. H. Medical College, Tundla, Agra, Uttar Pradesh, India. 2 Assistant Professor, Department of Microbiology, F. H. Medical College, Tundla, Agra, Uttar Pradesh, India.

${ }^{3}$ Assistant Professor, Department of Kulliyat, Hakeem Rais Unani Medical College and Hospital, Sambhal, Uttar Pradesh, India. 4 Professor, Department of Microbiology, JNMC, AMU, Aligarh, Uttar Pradesh, India.

\begin{tabular}{l}
\hline ABSTRACT \\
BACKGROUND \\
AmpC $\beta$-lactamases are clinically important cephalosporinases which confer resistance to cephamycins, penicillins, \\
aminoglycosides and $\beta$-lactam- $\beta$-lactamase inhibitor combinations and produced in several Enterobacteriaceae. The aim of this \\
study was to compare various phenotypic detection methods of AmpC $\beta$-Lactamases.
\end{tabular}

\section{MATERIALS AND METHODS}

This was a descriptive study. Three hundred multidrug-resistant bacterial isolates were tested for AmpC $\beta$-lactamase enzyme production. Cefoxitin $(30 \mu \mathrm{g})$ resistance was used as the screening test for AmpC enzyme detection. Phenotypic confirmation was done by conventional disk combination method (Cefoxitin/ cefoxitin + boronic acid), 3D extract method, double disk synergy test (DDST) and AmpC disk test.

\section{RESULTS}

All 300 strains were found to be AmpC positive by the screening test. Out of these 300 strains, 100 strains were positive by disk combination method, 107 strains by DDST, 111 strains by 3D extract method and 170 strains by AmpC disk test.

\section{CONCLUSION}

Cefoxitin resistance can be used as the screening test for AmpC. AmpC disc test is simple to perform. Many strains can be checked on single petri plate and get best results in comparison to other methods of AmpC detection. So, it can be used as a phenotypic method for detection of AmpC enzyme production in resource-limited settings, where genotypic detection methods are not available.

\section{KEY WORDS}

AmpC $\beta$-Lactamase, Double Disk Synergy Test, 3D Extract, Boronic Acid, AmpC Disk Test.

HOW TO CITE THIS ARTICLE: Rashid M, Naim H, Khalid M, et al. Comparison of different phenotypic methods for AmpC detection. J. Evolution Med. Dent. Sci. 2018;7(26):3032-3037, DOI: 10.14260/jemds/2018/681

\section{BACKGROUND}

AmpC $\quad \beta$-lactamases are clinically important cephalosporinases encoded on the chromosomes of many of the Enterobacteriaceae and a few other organisms where they mediate resistance to cephalothin, cefazolin, cefoxitin, most penicillins and $\beta$-lactamase inhibitor- $\beta$-lactam combinations. Microbes acquire these enzymes by horizontal gene transfer of the plasmid DNA. Persistent treatments with standard antibiotics lead to the origin of these enzymes worldwide in diverse species of Enterobacteriaceae such as Klebsiella pneumoniae, Klebsiella oxytoca, Escherichia coli, Salmonella spp. and Proteus mirabilis.(1-9) Plasmid-mediated AmpC $\beta$-lactamase are expressed constitutively in Enterobacteriaceae and are relatively rare.(10-11) Several AmpC enzyme producing bacteria are retrieved from hospitalised patients after some days of admission in the hospital. Although, more than two decades have passed since plasmid mediated AmpC- $\beta$-lactamases were discovered, still

'Financial or Other Competing Interest': None.

Submission 15-05-2018, Peer Review 08-06-2018,

Acceptance 14-06-2018, Published 25-06-2018.

Corresponding Author:

Dr. Huma Naim,

Department of Microbiology,

F. H. Medical College, Tundla, Agra,

Uttar Pradesh, India.

E-mail: huma06naim@gmail.com

DOI: $10.14260 /$ jemds $/ 2018 / 681$

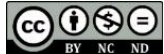

most clinical laboratories remain unaware of their clinical importance. As a result of which microorganisms producing them remain hidden and are mainly responsible for various nosocomial infections in hospital.

Numerous AmpC detection tests based on clinical microbiology techniques include screening for AmpC $\beta$ lactamases producing bacteria; modified three dimensional tests; disc approximation method; cefoxitin agar media (CAM) based assay; extraction of $\beta$-lactamase and analysis by isoelectric focusing; detection and characterisation of $\beta$ lactamases by PCR amplification and DNA sequencing; detection of AmpR regulatory gene and pulsed-field electrophoresis are available. Till now there is no recognised gold standard test for detection of AmpC $\beta$-lactamases.

It is highly desirable that clinical laboratories should undertake such additional tests capable of detecting latent resistance in time, so that they can effectively guide therapeutic as well as infection control strategies. The present study of phenotypic detection of AmpC $\beta$-lactamase producing bacteria will prevent unnecessary use of antibiotics and benefit patients by administration of appropriate antibiotics. This will also reduce the duration of hospital stay and treatments cost of the patient and thus help in reducing national health expenditure.

\section{Aims of the Study}

To compare various phenotypic detection methods of AmpC $\beta$-Lactamases. 


\section{MATERIALS AND METHODS}

\section{Study Group}

This descriptive study was performed at a tertiary care hospital in Western UP, India. 300 cefoxitin resistant strains of E. coli and Klebsiella spp. were subjected to various phenotypic methods of AmpC detection.

\section{Three-dimensional extract method for AmpC} detection(12)

\section{Material Required}

$90 \mathrm{~mm}$ petri plate, MHA plate, McFarland 0.5 standard, sterile cotton tipped swab, tryptic soy broth, scalpel blade, antimicrobial disk- Cefoxitin $(30 \mu \mathrm{g})$.

\section{Procedure}

$50 \mathrm{~mL}$ of $0.5 \mathrm{McF}$ arland bacterial suspensions prepared from an overnight blood agar plate was inoculated into $12 \mathrm{~mL}$ of tryptic soy broth and incubated for $4 \mathrm{hrs}$. at $35^{\circ} \mathrm{C}$. The cells are concentrated by centrifugation and crude enzyme preparations made by freeze thawing the cell pellets five times. The surface of a Mueller-Hinton agar (MHA) plate was inoculated with E. coli strains ATCC 25922 as described for the standard disk diffusion by NCCL guidelines 1997.(13) A 30 $\mu \mathrm{g}$ cefoxitin disk was placed on the inoculated agar. With a sterile scalpel blade, a slit beginning $5 \mathrm{~mm}$ from the edge of the disk was cut in the agar in an inward radial direction. By using a pipette, 25 - $30 \mu \mathrm{L}$ of enzyme was dispensed into the slit; beginning near the disk and moving inward avoiding overfull. The inoculated media was incubated overnight at $35^{\circ} \mathrm{C}$.

\section{Interpretation of Result}

Enhanced growth of the surface organism at the point where the slit intersected the zone of inhibition or indentation in the zone of inhibition was considered a positive 3D test result and was interpreted as evidence for the presence of AmpC $\beta$ lactamase.

\section{AmpC Disk Test(14) \\ Material Required}

Petri plates $90 \mathrm{~mm}$, MHA plate, Tris-EDTA, normal saline, Cefoxitin disk $(30 \mu \mathrm{g})$.

\section{Procedure}

AmpC disk was prepared in-house by applying $20 \mu \mathrm{L}$ of a 1:1 mixture of saline and 100X Tris-EDTA to sterile filter paper disks allowing the disks to dry and storing them at $2-8^{\circ} \mathrm{C}$. The surface of MHA plate was inoculated with a lawn of $E$. coli ATCC 25922 as for standard disk diffusion method. Immediately prior to use, AmpC disks were rehydrated with $20 \mu \mathrm{L}$ of saline and several colonies of each test organism was applied to the disk. A $30 \mu$ g cefoxitin disk was placed on the inoculated surface of the MHA plate. The inoculated AmpC disk was placed almost touching the antibiotic disk with the inoculated disk face in contact with the agar surface. The plate was incubated at $35^{\circ} \mathrm{C}$ for $16-18 \mathrm{hrs}$.

\section{Interpretation of Result}

An indentation or a flattening of the zone of inhibition indicates enzymatic inactivation of cefoxitin, which is interpreted as an AmpC producer strain. The absence of distortion indicates no significant inactivation of cefoxitin and the test strain is negative for AmpC $\beta$-lactamase production.

\section{Boronic Acid/ Cefoxitin Disk Combination Test(15) Material Required \\ Petri plates $90 \mathrm{~mm}$, MHA plate, McFarland 0.5 standard, normal saline, aminophenylboronic acid, Cefoxitin (30 $\mu \mathrm{g})$.}

\section{Preparation of Boronic Acid Disk (400 $\mu \mathrm{g}$ )}

$120 \mathrm{mg}$ of phenylboronic acid was dissolved in $3 \mathrm{~mL}$ of dimethyl sulfoxide. $3 \mathrm{~mL}$ of sterile distilled $\mathrm{H}_{2} \mathrm{O}$ was added to this solution. Now $20 \mu \mathrm{L}$ of the stock solution was dispensed onto a disk containing $30 \mu \mathrm{g}$ of cefoxitin. Disks were allowed to dry for 30 mins and used immediately or stored in air tight container at $4{ }^{\circ} \mathrm{C}$ and at $70^{\circ} \mathrm{C}$.

\section{Procedure}

Test strain was inoculated on MHA plate as mentioned in standard disk diffusion method. A disk containing $30 \mu \mathrm{g}$ of cefoxitin and $400 \mu \mathrm{g}$ of boronic acid was placed onto the agar plate.

\section{Interpretation of Result}

An organism that demonstrated a zone diameter around the disk containing cefoxitin and boronic acid that was $5 \mathrm{~mm}$ or greater than the zone diameter around the disk containing cefoxitin was considered an AmpC producer.

\section{Double Disk Synergy Test(16) Material Required}

$90 \mathrm{~mm}$ petri plates, MHA plate, McFarland 0.5 standard, sterile cotton tipped swabs, antimicrobial disks- boronic acid disk (400 $\mu \mathrm{g})$, Ceftazidime (30 $\mu \mathrm{g})$, Cefotaxime (30 $\mu \mathrm{g})$, Ceftriaxone $(30 \mu \mathrm{g})$ and Cefoxitin $(30 \mu \mathrm{g})$.

\section{Procedure}

MHA plate was used. Inoculum, incubation condition, incubation times were same as standard disk diffusion. A boronic acid disk was placed in the centre. Disk containing extended-spectrum cephalosporins was placed at a distance of $10 \mathrm{~mm}$ (center to center) from boronic acid disk.

\section{Interpretation of Result}

Production of an AmpC by the test organism was inferred by the presence of characteristic enhancement of the inhibition zone towards the boronic acid disk.

\section{RESULTS}

\section{AmpC $\beta$-Lactamase Detection by Screening Method $(\mathbf{n}=\mathbf{3 0 0})$}

Cefoxitin disk (30 $\mu \mathrm{g})$ was used for AmpC screening. All the 300 E. coli and Klebsiella isolates included in the study were tested for cefoxitin susceptibility and not a single isolate was found to be susceptible to cefoxitin $0(0 \%)$, i.e. all the 300 $(100 \%)$ isolates were resistant (Table 1$)$.

\section{AmpC $\beta$-Lactamase Detection by Disk Combination Method}

All the isolates of E. coli and Klebsiella, which were screened by using cefoxitin disk for detection of AmpC (Resistant) were tested with cefoxitin (Cn) Cefoxitin + Boronic acid (BA) disk combination methods for AmpC detection. Out of 300 isolates, this method detected $100(33.33 \%)$ isolates of E. coli and Klebsiella for AmpC production (Fig. 1; Table 2). 


\section{AmpC $\beta$-Lactamase Detection by 3D Extract Method}

All the 300 isolates were tested for AmpC detection by 3D extract method and this method detected 111 (37.00\%) E.coli and Klebsiella isolates for AmpC production. Out of this, E. coli and Klebsiella were 70 (37.63\%) and 41 (35.96\%) respectively (Fig. 2; Table 3).

\section{AmpC $\beta$-Lactamase Detection by DDST Method}

Various DDST combination ceftazidime/ boronic acid, cefotaxime/ boronic acid, ceftriaxone/ boronic acid were used for AmpC detection. Among these combinations ceftriaxone/ boronic acid detected maximum 107 (35.67\%) isolates followed by ceftazidime/ boronic acid 106 (35.33\%) and cefotaxime/ boronic acid 105 (35.00\%) from 300 isolates of E. coli and Klebsiella (Fig. 3; Table 4).

\section{AmpC $\beta$-Lactamase Detection by AmpC Disk Test}

AmpC disk test detected a total of 170 (56.67\%) isolates of $E$. coli and Klebsiella as AmpC $\beta$-lactamase producer out of a total of 300 isolates. By this method, 110 (59.19\%) isolates of E. coli and 60 (52.63\%) isolates of Klebsiella were found to be AmpC producer (Fig. 4; Table 5).

\section{Comparison of Various Methods of AmpC Detection $(\mathbf{n}=\mathbf{3 0 0})$}

Table 6 shows comparison of different methods of AmpC $\beta$ lactamase detection. AmpC disk test detected maximum number 170 (56.67\%) followed by 3D extract method 111 (37.00\%), DDST [(Ca/BA), (Ce/BA)] 108 (36.00\%) and Disk combination method $100(33.33 \%)$ out of $3003^{\text {rd }}$ generation cephalosporin resistant E. coli and Klebsiella isolates.

\begin{tabular}{|c|c|c|c|c|c|c|}
\hline $\begin{array}{c}\text { Screening } \\
\text { Method }\end{array}$ & $\begin{array}{c}\text { E. coli } \\
\text { No. (\%) }\end{array}$ & $\begin{array}{c}\text { Klebsiella } \\
\text { No. (\%) }\end{array}$ & Total & $\begin{array}{c}\text { E. coli } \\
\text { No. (\%) }\end{array}$ & $\begin{array}{c}\text { Klebsiella } \\
\text { No. (\%) }\end{array}$ & Total \\
\hline $\begin{array}{c}\text { Sensitive } \\
\text { Sensitive }\end{array}$ & & Resistant & Resistant & \\
\hline $\begin{array}{c}\text { disk } \\
\text { diffusion } \\
\text { method }\end{array}$ & $0(0.00)$ & $0(0.00)$ & 0 & 186 & 114 & $\begin{array}{c}300 \\
(100)\end{array}$ \\
\hline
\end{tabular}

Table 1. AmpC $\beta$-Lactamase detection by Screening Method

\begin{tabular}{|c|c|}
\hline Organism No. & Cn/ Cn + Boronic Acid (BA) No (\%) \\
\hline E. coli 186 & 65 \\
\hline Klebsiella 114 & 35 \\
\hline Total 300 & $100(33.33)$ \\
\hline
\end{tabular}

\begin{tabular}{|c|c|}
\hline Organism No. & 3D Extract Method No. (\%) \\
\hline E. coli 186 & $70(37.63)$ \\
\hline Klebsiella 114 & $41(35.96)$ \\
\hline Total 300 & $\mathbf{1 1 1 ( 3 7 . 0 0 \% )}$ \\
\hline Table 3. AmpC $\beta$-Lactamase detection by 3D Extract \\
Method \\
\hline
\end{tabular}

\begin{tabular}{|c|c|c|c|}
\hline & \multicolumn{3}{|c|}{ DDST No. (\%) } \\
\hline Organism & Ca/ BA & Ce/ BA & Ci/ BA \\
\hline E. coli 186 & $69(37.10)$ & $66(35.48)$ & $68(36.56)$ \\
\hline Klebsiella 114 & $37(32.46)$ & $39(34.21)$ & $39(34.21)$ \\
\hline Total 300 & $\mathbf{1 0 6}(\mathbf{3 5 . 3 3})$ & $\mathbf{1 0 5}(\mathbf{3 5 . 0 0 )}$ & $\begin{array}{c}\mathbf{1 0 7} \\
\mathbf{3 5 . 6 7})\end{array}$ \\
\hline \multicolumn{4}{|c}{ Table 4. AmpC $\boldsymbol{\beta}$-Lactamase detection by DDST Method } \\
\hline
\end{tabular}

\begin{tabular}{|c|c|}
\hline Organism No. & AmpC Disk Test No. (\%) \\
\hline E. coli 186 & $110(59.14)$ \\
\hline Klebsiella 114 & $60(52.63)$ \\
\hline Total 300 & $170(56.67)$ \\
\hline
\end{tabular}

\begin{tabular}{|c|c|c|c|c|}
\hline $\begin{array}{c}\text { Methods for } \\
\text { AmpC } \\
\text { Detection }\end{array}$ & $\begin{array}{c}\text { E. coli } \\
\mathbf{1 8 6}\end{array}$ & $\begin{array}{c}\text { Klebsiella } \\
\mathbf{1 1 4}\end{array}$ & $\begin{array}{c}\text { Total No. } \\
\text { (\%) }\end{array}$ & $\begin{array}{c}\text { P } \\
\text { value }\end{array}$ \\
\hline AmpC disk test & 110 & 60 & $170(56.67)$ & $>0.05$ \\
\hline $\begin{array}{c}\text { Disk } \\
\text { combination } \\
\text { method } \\
\text { (Cn/Cn+BA) }\end{array}$ & 65 & 35 & $100(33.33)$ & $>0.05$ \\
\hline DDST & $69(\mathrm{Ca} / \mathrm{BA})$ & $39(\mathrm{Ce} / \mathrm{BA})$ & $108(36.00)$ & $>0.05$ \\
\hline $\begin{array}{c}\text { 3D extract } \\
\text { method }\end{array}$ & 70 & 41 & $111(37.00)$ & $>0.05$ \\
\hline \multicolumn{5}{|c|}{ Table 6. Comparison of various methods of AmpC } \\
Detection \\
\hline
\end{tabular}

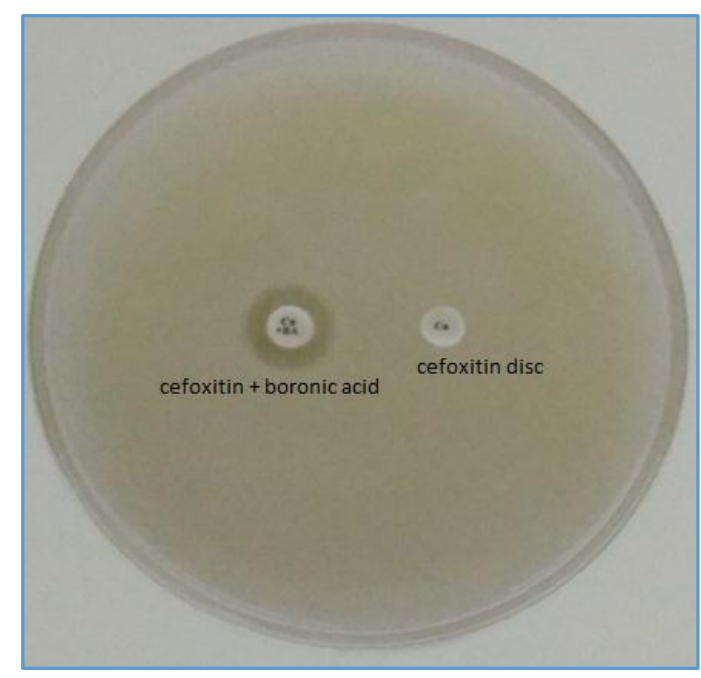

Figure 1. Disc Combination Method for detection of AmpC using Boronic Acid

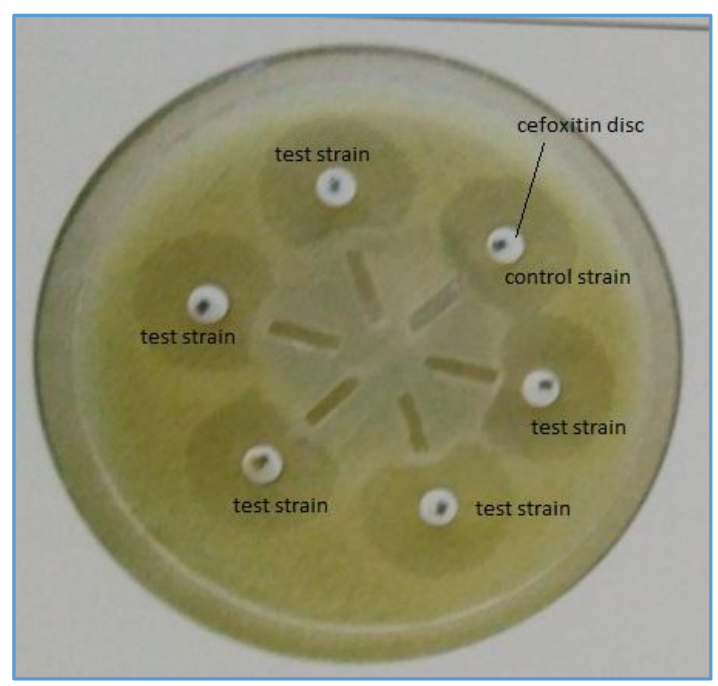

Figure 2. 3D Extract Method for detection of AmpC $\beta$-Lactamase 


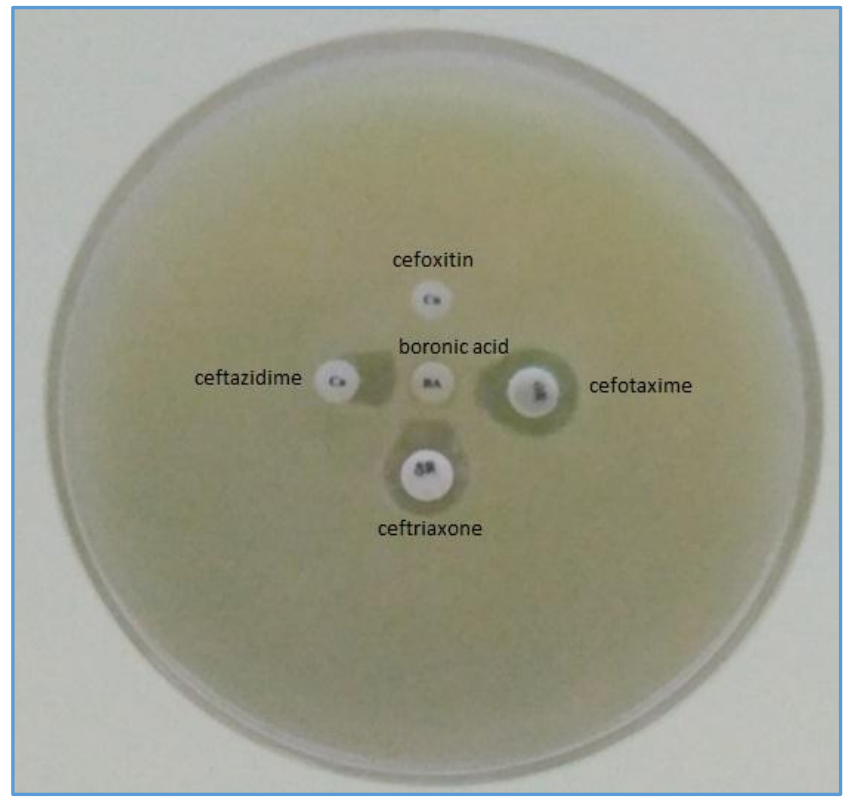

Figure 3. DDST for detection of AmpC by Boronic Acid

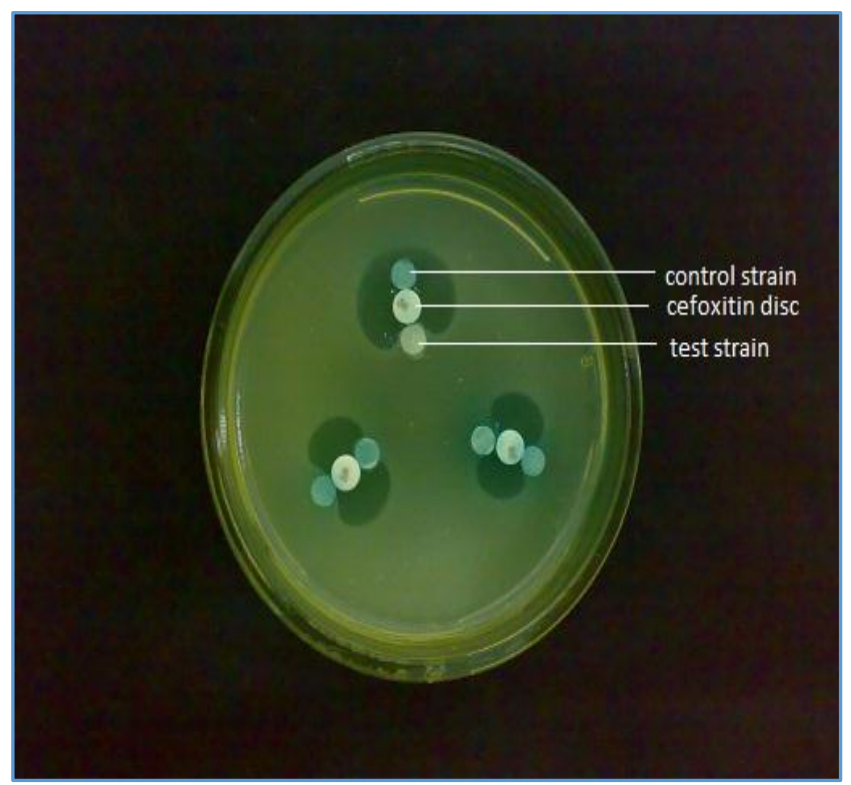

Figure 4. AmpC Disc Test for detection of AmpC $\beta$ Lactamase

\section{DISCUSSION}

A total of 300 resistant E. coli and Klebsiella isolates were screened for AmpC production with cefoxitin and it was found that all of them were resistant to cefoxitin. This may be due to AmpC production, porin loss(17-18) and/ or not all strains with AmpC enzymes meet NCCLS criteria for resistance to cephamycins and oxyimino-cephalosporins.(7) Some investigators have reported that cefoxitin resistance in general was a non-specific indicator of AmpC production.(19)

All the cefoxitin screened isolates were tested with boronic acid disk combination method (Reversible AmpC inhibitor).(15) This method confirmed AmpC production in $33.33 \%$ of isolates out of 300 cefoxitin screened positive isolates of E. coli and Klebsiella. Study carried by Coudron(15) showed that out of total 271 positive screened clinical isolates, 55 isolates showed $\mathrm{AmpC}$ production as was confirmed by PCR. Later these were subjected to boronic acid disk test, which detected presence of AmpC in 54 isolates.
Hemlatha et al(20) worked on cefoxitin/ boronic acid disk combination and showed that $47.3 \%$ of their resistant $E$. coli and Klebsiella isolates harbour AmpC enzyme.

AmpC $\beta$-lactamase production in cefoxitin resistant $E$. coli and Klebsiella was confirmed by three-dimensional extract methods. In our study, this method detected $37 \%$ E. coli and Klebsiella as AmpC producer. A different study carried out by Singhal et al(21) showed $36 \% \mathrm{AmpC}$ positive isolates out of 61 positive screen isolates by the three dimensional test. Study conducted by Ratna et al(22) showed that out of 520 isolates, 28 were resistant to cefoxitin and among these 16 isolates were positive by three dimensional extract method. In the study of Subha et al,(23) 84 Klebsiella isolates and 20 E. coli isolates that were found resistant (Zone diameter $<18 \mathrm{~mm}$ ) were subjected to three dimensional extract test. Out of 84 Klebsiella isolates, 20 (20.8\%) isolates of Klebsiella pneumoniae and 8 (40\%) isolates of Klebsiella oxytoca were positive AmpC producer by this method. And out of 20, 12 (37.5\%) isolates of E. coli resistant to cefoxitin showed the production of AmpC $\beta$-lactamase by three-dimensional extract tests.

In the present study, DDST using boronic acid (reversible AmpC inhibitor) was used for the detection of AmpC. All the cefoxitin screened positive isolates of E. coli and Klebsiella were subjected to DDST. Three DDST combinations were used i.e. ceftazidime and boronic acid, cefotaxime and boronic acid and ceftriaxone and boronic acid. Out of these combinations, ceftriaxone and boronic acid detected highest number of AmpC producer isolates (35.67\%) followed by ceftazidime and boronic acid (35.33\%) and least number by cefotaxime and boronic acid (35.00\%). So almost all the third generation cephalosporins used in this test detected almost same number of AmpC producer, but slightly higher for ceftriaxone followed by ceftazidime and least number for cefotaxime. Power et al(24) first described the potentiating effect of boronic acid to the antimicrobial activity of ceftazidime and Liebana et al(25) used this synergism test for confirmation of the presence of an AmpC like enzyme.

AmpC disk test was also used for the detection of AmpC in cefoxitin screen positive isolates of E. coli and Klebsiella. Overall, this test detected $56.67 \%$ of screened positive isolates as AmpC producer. According to Jennifer et al this test was found to be highly sensitive, specific and convenient means for detection of plasmid mediated AmpC $\beta$-lactamases. Singhal et al(21) also reported in their study that this method was sensitive and specific for the detection of AmpC.

In the present study different methods of AmpC detection was used, i.e. AmpC disk test, inhibitor (boronic acid) disk combination method, DDST by using boronic acid and 3D extract method. All the methods detected more E. coli as AmpC producer than Klebsiella. So, it was obvious that AmpC production was more prevalent in E. coli than Klebsiella. Maximum number of AmpC production was detected by AmpC disk test (56.67\%) followed by 3D extract method (37.00\%), DDST method using boronic acid showed $36.00 \%$ and least number by cefoxitin and boronic acid disk combination (33.33\%). Except AmpC disk test all the other methods of AmpC detection used in the present study detected almost same number of AmpC producer. So, among the entire AmpC detection test used in this study, AmpC disk test was the best test for the detection of AmpC in clinical strains of E. coli and Klebsiella. Singhal et al(20) in their study 
compared AmpC disk test with 3D extract method for AmpC detection. In their study 22 isolates (8\%) out of the 272 isolates or $36 \%$ of the $61 \mathrm{AmpC}$ screen positive isolates, 22 isolates which were positive by $3 \mathrm{D}$ extraction method also showed positive results by AmpC disk test. Indentation indicating strong AmpC producer was observed in 15 isolates, whereas flattening (weak AmpC) was observed in 7 isolates. Three indeterminate isolates (3D tests) also showed flattening in AmpC disk test indicating weak AmpC enzyme. For detection of AmpC class of $\beta$-lactamases, no satisfactory technique has been established till date, although various researchers have tried the 3D test with different modifications. This technique first described by Thomson et al,(26) has its own limitations, despite being increasingly sensitive. In their study they used an AmpC disk test which is an easier, reliable and rapid method of detection of isolates that harbour AmpC $\beta$-lactamases. This suggests that AmpC disk test can be used for routine screening of the AmpC enzymes in clinical laboratory.(21,14)

\section{CONCLUSION}

From our study, it can be concluded that cefoxitin resistance can be used as the screening test for AmpC. AmpC disc test is easy to perform. Many strains can be checked on single petri plate and get best results followed by 3D extract method, DDST and disc combination method. Thus, AmpC disc test can be used above all the other available methods for phenotypic detection of AmpC enzyme production in resource-limited conditions where genotypic detection methods are not available.

\section{REFERENCES}

[1] Alvarez M, Tran JH, Chow N, et al. Epidemiology of conjugative plasmid-mediated AmpC $\beta$-lactamases in the United States. Antimicrob Agents Chemother 2004;48(2):533-7.

[2] Literacka E, Empel J, Baraniak A, et al. Four variants of the Citrobacter freundii AmpC-type cephalosporinases, including novel enzymes CMY-14 and CMY-15 in a Proteus mirabilis clone widespread in Poland. J Antimicrob Agents Chemother 2004;48(11):4136-43.

[3] Miriagou V, Tzouvelekis LS, Villa L, et al. CMY-13, a novel inducible cephalosporinase encoded by an Escherichia coli plasmid. J Antimicrob Agents Chemother 2004;48(8):3172-4.

[4] Mulvey MR, Bryce E, Boyd DA, et al. Molecular characterization of cefoxitin-resistant Escherichia coli from Canadian hospitals. J Antimicrob Agents Chemother 2005;49(1):358-65.

[5] Nakano R, Okamoto R, Nakano Y, et al. CFE-1, a novel plasmid-encoded AmpC $\beta$-lactamase with an ampR gene originating from Citrobacter freundii. J Antimicrob Agents Chemother 2004;48(4):1151-8.

[6] Navarro F, Perez-Trallero E, Marimon JM, et al. CMY-2producing Salmonella enterica, Klebsiella pneumoniae, Klebsiella oxytoca, Proteus mirabilis and Escherichi coli strains isolated in Spain (October 1999 December 2000). J Antimicrob Chemother 2001;48(23):383-9.
[7] Philippon A, Arlet G, Jacoby GA. Plasmid-determined AmpC-type $\beta$-lactamases. J Antimicrob Agents Chemother 2002;46(1):1-11.

[8] Yong D, Lim Y, Song W, et al. Plasmid-mediated inducible AmpC $\beta$-lactamase (DHA-1)-producing Enterobacteriaceae at a Korean hospital: wide dissemination in Klebsiella pneumoniae, Klebsiella oxytocaand emergence in Proteus mirabilis. Dia Microbio Infect Dis 2005;53(1):65-70.

[9] D'Andrea MM, Nucleo E, Luzzaro F, et al. CMY-16, a novel acquired AmpC-type $\beta$-lactamase of the CMY/LAT lineage in multifocal monophyletic isolates of Proteus mirabilis from Northern Italy. J Antimicrob Agents Chemother 2006;50(2):618-24.

[10] Bush K, Jacoby GA, Medeiros AA. A functional classification scheme for $\beta$ - lactamases and its correlation with molecular structure. J Antimicrob Agents Chemother 1995;39(6):1211-33.

[11] Dunne EF, Fey PD, Kludt P, et al. Emergence of domestically acquired ceftriaxone-resistant Salmonella infections associated with AmpC $\beta$ lactamase. JAMA 2000;284(24):3151-6.

[12] Coudron PE, Moland ES, Thomson KS. Occurrence and detection of AmpC $\beta$-lactamases among Escherichia coli, Klebsiella pneumonia and Proteus mirabilis isolates at a veterans medical center. J Clin Microbiol 2000;38(5):1791-6.

[13] National Committee for Clinical Laboratory. Standards Performance standards for antimicrobial disk susceptibility tests. 6th edn. Approved standard M2A6 (M100-S7). National Committee for Clinical Laboratory Standards, Wayne, Pa. 1997.

[14] Black JA, Moland ES, Thomson KS. AmpC disk test for detection of plasmid-mediated AmpC $\beta$-lactamases in Enterobacteriaceae lacking chromosomal AmpC $\beta$ lactamases. J Clin Microbiol 2005;43(7):3110-3.

[15] Coudron PE. Inhibitor-based methods for detection of plasmid-mediated $\quad$ AmpC $\quad \beta$-Lactamases in Klebsiella spp., Escherichia coli and Proteus mirabilis. J Clin Microbiol 2005;43(8):4163-7.

[16] Yagi T, Wachino J, Kurokawa H, et al. Practical methods using boronic acid compounds for identification of class $\mathrm{C} \quad \beta$-Lactamaseproducing Klebsiella Pneumoniae and Escherichia coli. J Clin Microbiol 2005;43(6):2551-8.

[17] Martinez-Yamout M, Legge GB, Zhang O, et al. Solution structure of the cysteine-rich domain of the Escherichia coli chaperone protein DnaJ.J Mol Biol 2000;300(4):805-18.

[18] Hernandez-Alles S, Conejo MD, Pascual A, et al. Relationship between outer membrane alterations and susceptibility to antimicrobial agents in isogenic strains of Klebsiella pneumoniae. J Antimicrobial Chemotherapy 2000;46(2):273-7.

[19] Steward CD, Rasheed JK, Hubert SK, et al. Characterization of clinical isolates of Klebsiella penumoniae from 19 laboratories using the National Committee for Clinical Laboratory Standards extended-spectrum $\beta$-lactamase detection methods. J Clin Microbiol 2001;39(8):2864-72. 
[20] Hemlatha V, Sekar U, Kamat V. Detection of metallo $\beta$ lactamase producing Pseudomonas aeruginosa in hospitalized patients. Indian J Med Res 2005;122(2):148-52.

[21] Singhal S, Mathur T, Khan S, et al. Evaluation of methods for AmpC $\beta$-Lactamase in gram negative clinical isolates from tertiary care hospitals. Indian J Med Microbiol 2005;23(2):120-4.

[22] Ratna AK, Menon I, Kapur I, et al. Occurrence \& detection of Amp C $\beta$-lactamases at a referral hospital in Karnataka. Indian J Med Res 2003;118:29-32.

[23] Subha A, Devi VR, Ananthan S. AmpC $\beta$-lactase producing multi drug resistant strains of Klebsiella spp., and Escherichia coli isolated from children under five in Chennai, India. Indian J Med Res 2005;117:13-8.
[24] Power P, Radice M, Barberis C, et al. Cefotaximehydrolysing beta lactamases in Morganella morganii. Eur J Clin Microbiol Infect Dis 1999;18(10):743-7.

[25] Liebana E, Gibbs M, Clouting C, et al. Characterization of $\beta$-lactamases responsible for resistance to extended-spectrum cephalosporins in Escherichia coli and Salmonella enteric strains from food-producing animals in the United Kingdom. Microb Drug Resist 2004;10(1):1-9.

[26] Thomson KS, Mejghlo ZA, Pearce GN, et al. 3Dimensional susceptibility testing of $\beta$-lactam antibiotics. J Antimicrob Chemother 1984;13(1):4554 . 